\title{
Early Recognition of Endometriosis Depending on Severity of Dysmenorrhea among Adolescent Girls
}

\author{
Youssria Elsayed Yousef ${ }^{1, ~ *, ~ S a l w a ~ A l i ~ M a r z o u k ~}{ }^{2}$, Hameida Alam Eldien ${ }^{3}$, Howieda Fouly ${ }^{3}$, \\ Neama Mohamed El Magrab ${ }^{4}$, Safaa Rashad Mahmoud ${ }^{4}$ \\ ${ }^{1}$ Departments of Pediatric Nursing, Faculty of Nursing, Sohag University, Sohag, Egypt \\ ${ }^{2}$ Departments of Pediatric Nursing, Faculty of Nursing, Assiut University, Assiut, Egypt \\ ${ }^{3}$ Departments of Obstetrics and Gynecology Nursing, Faculty of Nursing, Assuit University, Assiut, Egypt \\ ${ }^{4}$ Departments of Community Health Nursing, Faculty of Nursing, Assiut University, Assiut, Egypt
}

Email address:

youssria_elsayed@yahoo.com (Y.E. Yousef)

${ }^{*}$ Corresponding author

\section{To cite this article:}

Youssria Elsayed Yousef, Salwa Ali Marzouk, Hameida Alam Eldien, Howieda Fouly, Neama Mohamed El Magrab, Safaa Rashad Mahmoud. Early Recognition of Endometriosis Depending on Severity of Dysmenorrhea Among Adolescent Girls. American Journal of Nursing Science. Vol. 8, No. 4, 2019, pp. 191-199. doi: 10.11648/j.ajns.20190804.21

Received: April 15, 2019; Accepted: June 17, 2019; Published: July 16, 2019

\begin{abstract}
Background: Endometriosis is recognized as the 'disease of young girls' because it seems to be more common in young girls. Early diagnosis is greatly essential to receive appropriate treatment and avoid complications. Aim of the study: to evaluate severe dysmenorrhea for early recognition of endometriosis among adolescent girls. Subject and Methods: Crosssectional descriptive design was used in this study. The study included 571 adolescent girls from 4 representative elementary schools in Assiut city. A structured Questionnaire was developed by the investigators and included four parts: Part I: demographic data; Part II: menstrual pattern: Part III. Pain history including: a. pain characteristics. b. Menstrual pain associating symptoms: c. Pain level: using of Horizontal Visual Analog Scale (VAS) 0-10 points. Part IV: finding of Transabdominal ultrasound (AUS) for those with severe dysmenorrhea. Field work: The study passed through three phases including assessment, implementation, and follow up phases with a period of 7 months. Results: the majority of the girls were between the age of $13-14$ years. According to VAS, severe dysmenorrhea was reported in 68 girls (15\%). Positive ultrasonography findings suggestive of endometriosis were reported among $57.4 \%$ of girls who had severe dysmenorrhea. The majority $(71.2 \%)$ of those girls with severe dysmenorrhea responded to hormonal treatment while $28.2 \%$ not responded. There was a positive correlation between number of symptoms associating dysmenorrhea and the pain level. Conclusions and recommendations: Moderate and severe dysmenorrhea are common among adolescent. Those girls who had severe dysmenorrhea and more than five symptoms associating dysmenorrhea might be suspected to have endometriosis. Further large scale study is essential with the use of more informative investigations as MRI and laparoscopy to gain accurate estimate of the prevalence of the disease and its types.
\end{abstract}

Keywords: Endometriosis, Dysmenorrhea, Adolescent Girls

\section{Introduction}

Endometriosis is a complex gynacologic issue described by benign proliferation of ectopic endometrial organs and stroma in the peritoneal hole, with dysmenorrhea, pelvic pain, and barrenness and different manifestations principally among ladies of conceptive age [1].

Endometriosis is accounted for to influence almost 176 million women of reproductive age around the world, with a pinnacle of rate somewhere in the range of 24 and 29 years. Usually among $10 \%$ in women in the conceptive age, 20 half in ladies experiencing barrenness and about $90 \%$ in women grumbling of interminable pelvic pain [2].

Dysmenorrhea might be essential (absence of pelvic pathology) or auxiliary due basic pathology; endometriosis is one of them. Dysmenorrhea influences 40- half of young 
people with serious structures among $15 \%$ of them. Endometriosis ought to be considered as a reason if excruciating periods began one year after menarche [3].

Adolescent endometriosis is a thought little of medical issue especially in creating nations. The attention to young girls, women, guardians, nurses, general specialists, and gynecologists by the issue of endometriosis is viewed as a foundation in its initial finding in the youthful young ladies. What's more, for acknowledgment of endometriosis, human services suppliers ought to consider it in the differential conclusion when managing young women experiencing pelvic torment and dysmenorrhea [4]. Usually, endometriosis is a reason for regular school absence among juvenile young girls who for the most part utilize oral preventative medications to control serious dysmenorrhea [5].

Fong, et al, (2017) announced that, postponed finding of endometriosis keeps on being serious issue that prompts late treatment. Numerous causes were portrayed for this postponement, social unacceptance of visiting gynecologists by youthful unmarried young girls for menstrual issues particularly in upper Egypt; inaccessibility of nearby examination, trans-vaginal ultrasound and laparoscopy; notwithstanding acknowledgment of agonizing monthly cycle as normal [6].

Another reason for postponed analysis was depicted; the non explicit clinical introduction of endometriosis as ceaseless pelvic agony, urinary or gastrointestinal manifestations. They included that, the clinical conclusion of endometriosis might be deferred to 7-10 years from the first symptom [7]. The finding of endometriosis depends certainly on laparoscopy and/or careful intercession and histopathological proof. In any case, imaging modalities, attractive reverberation imaging (MRI) and ultrasound (US) either trans-stomach or trans-vaginal are basic for treatment convention. X-ray is better than physical examination and transvaginal ultrasound (TVUS) for assessment and area of endometriosis particularly the profound penetrating type [8$10]$.

Endometriosis ought to be associated when at least one with the accompanying criteria are experienced; unending pelvic torment, dysmenorrhea, dysuria, hematuria or excruciating solid discharge. At the point when these side effects are serious, relentless or intermittent, reference to endometriosis focus or gynecology master is compulsory for further investigations [11].

Endometriosis that is concised to the uterus is called adenomyosis. What's more, there are three primary sorts outside the uterus including superficial implants (powder burns), endometriomas (chocolate cysts) and the third kind is deep infiltrative endometriosis (DIE) when endometrial tissue is found outside the stomach pit or penetrating pelvic gastrointestinal and urological systems [12].

As there are no complete noninvasive demonstrative apparatuses pathognomonic for endometriosis, it is required for cutting edge professional attendants (APNs) to have enough mindfulness and information about the ailment including its etiology, clinical introduction, determination, current treatment and anticipation. What's more, APNs may play an imperative strong job for young girls with the malady to encourage care quality and improve the nature of the life [13].

\subsection{Aim of the Study}

This study aimed to evaluate severe dysmenorrhea for early recognition of endometriosis among adolescent girls.

\subsection{Research Quotations}

What are the different levels of dysmenorrhea among adolescent girls?

Is there a role of severe dysmenorrhea to early recognize endometriosis among adolescent girls?

\subsection{Conceptual Framework}

This study assessed pain degree by visual analog scale (VAS) and pain features. The severe pain level among school girls was hypothesized to be an indicator of the possible presence of endometriosis. Abdominal ultrasound (AUS) was used as an initial screening tool to add to this hypothesis.

\section{Subject and Methods}

\subsection{Research Design}

Cross-sectional descriptive design was used in this study.

\subsection{Setting}

The study included a sample of adolescent girls in Assiut city. The selected elementary schools represented all geographic areas of Assiut city including both private schools (Bader and El-tahreer) and public schools (Huda Sharawey and University school).

Sample size: Adolescent girls were selected using cluster sampling technique. All adolescent girls who accepted to participate from the targeted elementary schools were included in the study (they were 634 girls). The participating girls were recruited with the following inclusion criteria: 1) had menstruation more than six months. 2) age range between 12-15 years. Adolescent girls who refused to participate in the research were excluded from the study.

\subsection{Tools}

One tool was used to accomplish this study:

A structured Questionnaire: It was developed by the investigators, it included four parts:

1. Part I: Demographic data, such as age, residence, mother and father education and occupation.

2. Part II: Menstrual pattern: age at menarche, duration of the flow, regularity and duration of menstrual cycle, menstrual pain for mother and family history of endometriosis.

3. Part III. Pain history: it consisted of three sub-items:

A. Pain characteristics: age at first menstrual pain, its duration, time of pain, medications given to alleviate 
and who described them.

B. Menstrual pain associating symptoms: as irregular menstruation, menorrhagia, pain during defecation, pain during urination, backache, pain during sitting and pain down the legs $[4,14]$.

C. Pain level: was assessed using of Horizontal Visual Analog Scale (VAS) 0-10. A score of 0 was defined as no pain and 10 was defined as the most severe intolerable pain. The girls were asked to rate the level of pain by making a mark on the future biopsy. The scores received from the scale were classified into mild dysmenorrhea if it was between 1-3 points, moderate between $4-7$ points, and severe between 8 10 points [15].

4. Part IV. Trans-abdominal ultrasound (AUS): It was used to scan girls with severe dysmenorrhea and suspected to have endometriosis. The pelvic organs were visualized by AUS using $3-5 \mathrm{MHz}$ transducer at a depth of $10-$ $15 \mathrm{~cm}$ through full urinary bladder, which acts as an acoustic window.

Validity: The tool was prepared, translated and reviewed to ascertain their content validity by five experts in nursing and gynacology. The recommended modifications were done accordingly, and then the tool was designed in its final format. The validity was $97.6 \%$.

The reliability was assessed in the pilot study by test retest and it was estimated by alpha Cronbach's test for the tool and its result was $\mathrm{R}=0.883$.

\subsection{Methods}

Administrative approval was obtained from the responsible personnel (in the Ministry of Education) to carry out the study after explaining the purpose of study. Meetings with elementary school managers were carried out to explain the importance and objectives of the study to gain their cooperation and to allow the release of girls to attend the program during minimal workload activities.

\subsection{Pilot Study}

After developing the tool, a pilot study was implemented on 63 adolescent girls to test tool clarity, completeness and to determine the required time. According to the results of pilot, the needed modifications were done and they were excluded from the study. So the final number of participating girls was 571.

\subsection{Field Work}

The study passed through three phases including assessment, implementation, and follow up phases.

Assessment phase: In this phase, data were collected during the period from January to July 2018 in the selected elementary schools from 9 am to $2 \mathrm{pm}$, three days per week (according to students' schedule). A questionnaire sheet was designed and translated into simple arabic language to be given to participating girls.

Implementation phase: In this phase, girls recruited from the selected schools (571 girls) were informed how to fill the questionnaires and answer the questions. The girls completed questionnaire in the presence of a member of the research team. The duration for completing the questionnaire ranged between 30 and 40 minutes.

After girls finished the questionnaire, the researchers provided clear and concise information through oral instructions and written pamphlet about endometriosis (definition, clinical features, diagnosis, management and prognosis).

Follow-up phase: In this phase, those girls who were suspected to have endometriosis received combined oral hormonal pills continuous for 3 month, according to gynecologist description. After three months, those girls were re-evaluated by asking about history of pain level and associating symptoms and by using VAS and the results were recorded.

Ethical consideration:

Complete confidentiality of the obtained data was ensured throughout steps of the work. The study maneuver could not entail any harmful effects on participant. Each girls agreed to participate had their parent consent. The questionnaire was nameless-coded to maintain neutrality. The codes were used to identify girls who required AUS and follow-up.

Statistical Analysis:

Statistical analysis was done using SPSS-16 statistical software package and Excel for figures. Data were presented using descriptive statistics in the form of frequencies and percentages for qualitative variables, and means and standard deviations for quantitative variables. Quantitative continuous data were compared by using student t-test in case of comparisons between the mean scores of the studied groups. Qualitative studied variables were compared using Chisquare test. Statistical significance was considered at $\mathrm{P}$ value $<0.05$.

\section{Results}

Figure 1 The total number of participating adolescent girls was 571. According to VAS, severe dysmenorrhea was reported in 68 girls (15\%). Positive ultrasonography findings suggestive of endometriosis was reported in $57.4 \%$ (39 out of 69) of girls who had severe dysmenorrhea. AUS findings suggestive of endometriosis were cystic and solid masses with homogenous diffuse echos of the ovaries, pelvic adhesions between organs including urinary bladder and bowel loops, cystic masses adherent to the uterus. The majority (28 out of $39,71.2 \%$ ) of those girls with severe dysmenorrhea responded to hormonal treatment while $28.2 \%$ (11 out of 39) not responded. 
Table 1. Demographic characteristics of participating adolescents girls $(n=571)$.

\begin{tabular}{llc}
\hline & No. & \% \\
\hline Age (years) & 436 & 76.4 \\
$12-<14$ & 135 & 23.6 \\
$14-15$ & $13.19 \pm 0.65$ & $(12.0-15.0)$ \\
Mean \pm SD (Range) & & \\
Mother education & 162 & 28.4 \\
Illiterate & 107 & 18.7 \\
Read \& write & 29 & 5.1 \\
Basic education & 185 & 32.4 \\
Secondary school & 88 & 15.4 \\
University & & \\
Father education & 47 & 8.2 \\
Illiterate & 147 & 25.7 \\
Read \& write & 33 & 5.8 \\
Basic education & 220 & 38.5 \\
Secondary school & 124 & 21.7 \\
University & & \\
Mother occupation & 93 & 16.3 \\
Working & 478 & 83.7 \\
Not working & & 82.7 \\
Father occupation & 472 & 17.3 \\
Working & 99 & \\
Not working & & \\
\hline
\end{tabular}

Demographic characteristics of the adolescents girl presented in table 1. It was noticed that, the majority of the girls between the age of $13-14$ years $(76.4 \%)$ with mean age 13.19 years.

Table 2. Menstrual pattern among participating adolescents girls $(n=571)$.

\begin{tabular}{llc}
\hline & No. (571) & $\%$ \\
\hline Age at menarche & & \\
$<13$ & 183 & 32.0 \\
13 & 249 & 43.6 \\
$>13$ & 139 & 24.3 \\
Mean \pm SD (Range) & $12.88 \pm 0.89(11.0-15.0)$ \\
Regularity of menstrual cycle & & \\
Regular & 226 & 39.6 \\
Irregular & 345 & 60.4 \\
Duration of the flow & & \\
Mean \pm SD (Range) & $4.44 \pm 1.07(2.0-7.0)$ \\
Menstrual cycle duration (days) & & \\
Mean \pm SD (Range) & $25.59 \pm 1.85(23.0-30.0)$ \\
Family history of endometriosis & & \\
Yes & 23 & 4.0 \\
No & 548 & 96.0 \\
Dysmenorrhea & & 79.3 \\
Yes & 453 & 20.7 \\
No & 118 &
\end{tabular}

Table 2 describes the menstrual pattern of participating girls including age at menarche, regularity and duration of menstrual cycle and family history of endometriosis. Only 23 girls $(4.0 \%)$ had a positive family history of endometriosis. More than three quarters $(79.3 \%)$ of the adolescent girls reported dysmenorrhea.
Table 3. Pain characteristics among participating adolescents girls with dysmenorrhea $(n=453)$.

\begin{tabular}{llc}
\hline & No. (453) & \% \\
\hline Age at first menstrual pain & & \\
$12-<14$ & 294 & 64.9 \\
$14-15$ & 159 & 35.1 \\
Mean \pm SD (Range) & $13.22 \pm 0.87(12.0-15.0)$ \\
Duration of pain & & \\
All days & 193 & 42.6 \\
Some days & 260 & 57.4 \\
Time of pain & & \\
Before period & 181 & 40.0 \\
During and after & 212 & 46.8 \\
Before, during and after & 60 & 13.2 \\
Level of pain & & \\
Mild & 157 & 34.7 \\
Moderate & 228 & 50.3 \\
Severe & 68 & 15.0 \\
Mean \pm SD (Range) & $4.49 \pm 2.32(1.0-10.0)$ \\
Alleviating measures & & \\
Analgesics & 65 & 14.3 \\
Hot drinks & 46 & 10.2 \\
Shower & 15 & 3.3 \\
Nothing & 327 & 72.2 \\
Who described & & 15.4 \\
Physician & 10 & 84.6 \\
Relatives & 55 &
\end{tabular}

As illustrated in Table 3 the majority of participating girls (79.3\%) experienced menstrual pain and about two thirds $(64.9 \%)$ of them had the first menstrual pain at the age between 12 and less than 14 years with a mean of 13.22 years.

Table 4. Frequency of symptoms associating dysmenorrhea among participating adolescents girls $(n=453)$.

\begin{tabular}{lll}
\hline Items & No. & \% \\
\hline Menorrhagia & 80 & 17.6 \\
Irregular menstruation & 248 & 54.7 \\
Early start of the menstrual cycle & 45 & 9.9 \\
Pain during defecation & 117 & 25.8 \\
Pain during urination & 140 & 30.9 \\
Nausea, vomiting, diarrhea or constipation & 130 & 28.6 \\
Back ache & 298 & 65.7 \\
Pain during sitting & 179 & 39.5 \\
Pain down the legs & 113 & 24.9 \\
\hline
\end{tabular}

Regarding the pain level, severe dysmenorrhea was reported among $15 \%$, of participating girls. The Frequency of symptoms associating dysmenorrhea among adolescent girls is shown in table 4 Irregular menstruation was reported by $43.4 \%$ of the girls and $31.3 \%$ reported pain during sitting. More than one quarter of the girls reported pain during urination and pain during defecation $(24.5 \%$ and $20.5 \%$, respectively) while pain down the legs was found among $19.8 \%$ of the girls. 


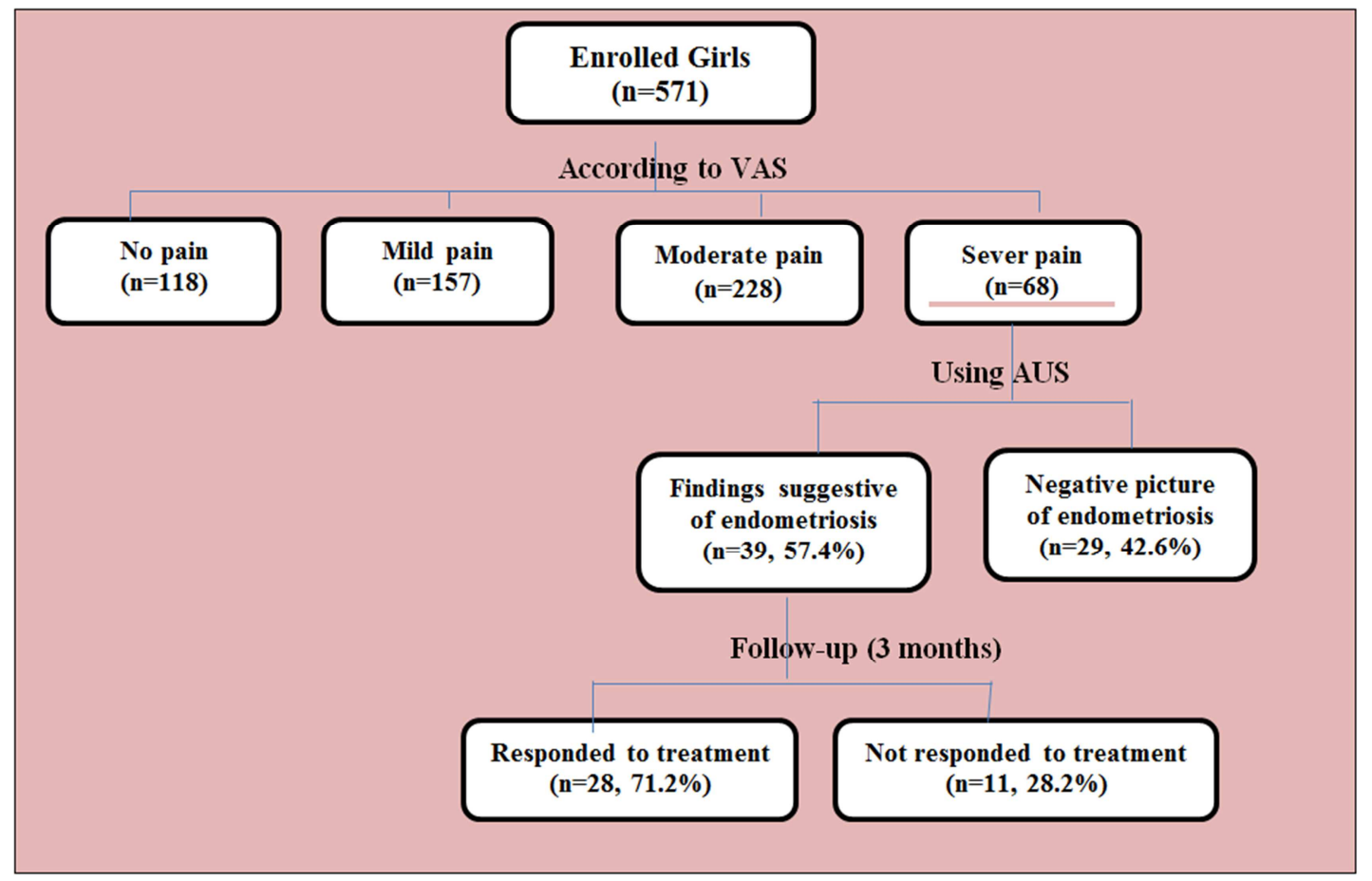

VAS: Visual Analog Scale AUS: Abdominal ultrasound.

Figure 1. Tegorization of participating girls according to VAS, AUS and response to treatment.

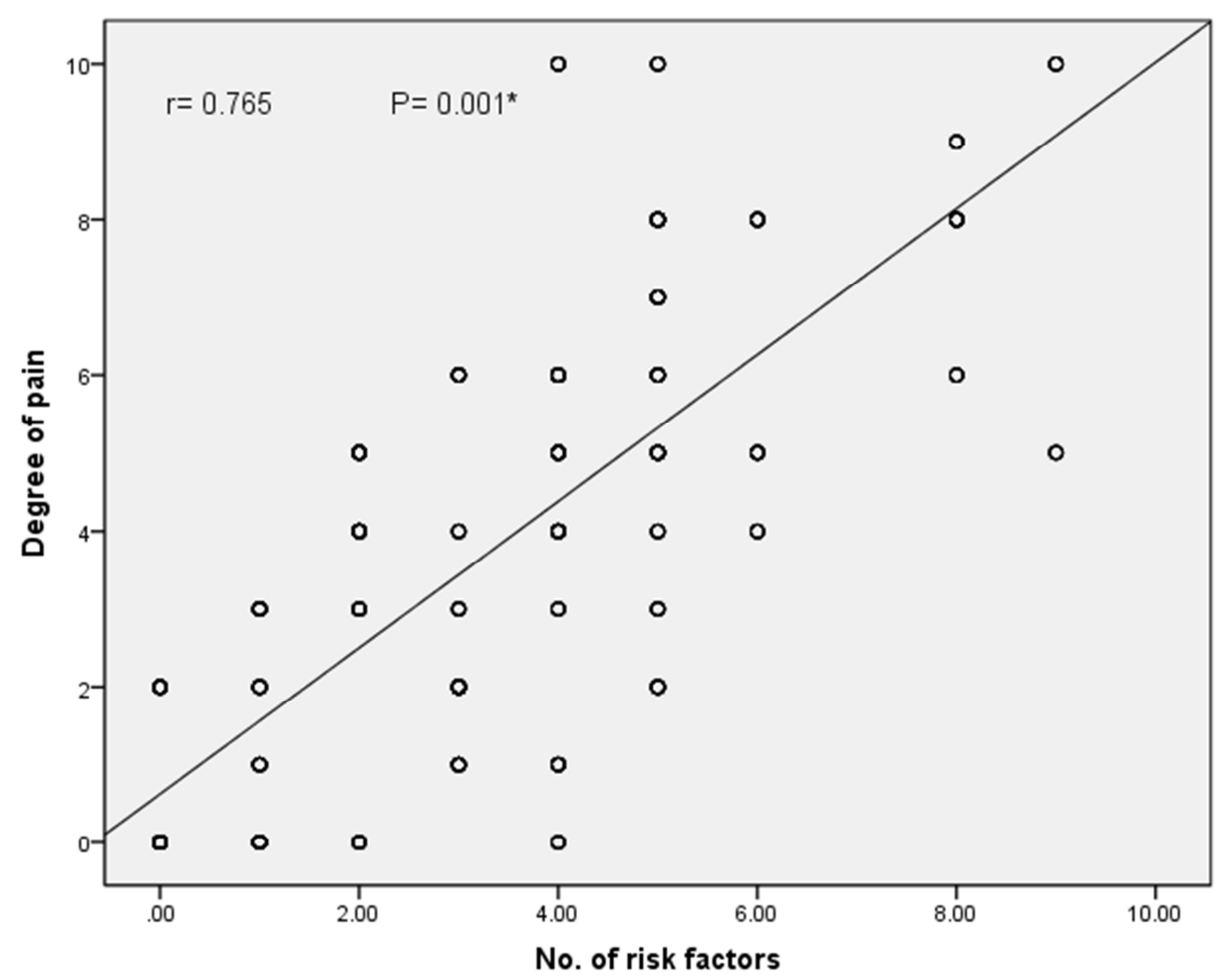

Figure 2. Correlation between number of symptoms associating dysmenorrhea (risk factors) and degree of pain.

Figure 2: described the correlation between the number of symptoms associating dysmenorrhea and pain level. There was a positive correlation between number of symptoms associating dysmenorrhea and pain level with statistically significant difference $(\mathrm{P}=0.001 / \mathrm{r}=0.758)$.

Table 5 shows the symptoms associating dysmenorrhea suggestive of endometriosis. It was found that, girls suffering from pelvic pain at any time, menorrhagia, irregular menstruation, pain during defecation, back ache and pain during sitting are suspected to have endometriosis (p: 0.003, $0.00,0.016,0.005,0.00$ and 0.04 , respectively). 
Table 5. Symptoms associating dysmenorrhea suggestive of endometriosis.

\begin{tabular}{|c|c|c|c|c|c|c|}
\hline \multirow{3}{*}{ Symptoms associating dysmenorrhea } & & \multicolumn{4}{|c|}{ Suggested Endometriosis } & \multirow{3}{*}{ P-value } \\
\hline & & \multicolumn{2}{|c|}{ Yes $(\mathrm{n}=39)$} & \multicolumn{2}{|c|}{ No $(n=29)$} & \\
\hline & & No. & $\%$ & No. & $\%$ & \\
\hline \multirow{2}{*}{ Pelvic pain at any time } & Yes & 17 & 85.0 & 3 & 15.0 & \multirow{2}{*}{$0.003 *$} \\
\hline & No & 22 & 45.8 & 26 & 54.2 & \\
\hline \multirow{2}{*}{ Menorrhagia } & Yes & 22 & 100.0 & 0 & 0.0 & \multirow{2}{*}{$0.000^{*}$} \\
\hline & No & 17 & 37.0 & 29 & 63.0 & \\
\hline \multirow{2}{*}{ Irregular menstruation } & Yes & 34 & 65.4 & 18 & 34.6 & \multirow[b]{2}{*}{$0.016^{*}$} \\
\hline & No & 5 & 31.3 & 11 & 68.8 & \\
\hline \multirow{2}{*}{ Early start of the menstrual cycle } & Yes & 5 & 100.0 & 0 & 0.0 & \multirow{2}{*}{0.067} \\
\hline & No & 34 & 54.0 & 29 & 46.0 & \\
\hline \multirow{2}{*}{ Pain during defecation } & Yes & 18 & 81.8 & 4 & 18.2 & \multirow{2}{*}{$0.005^{*}$} \\
\hline & No & 21 & 45.7 & 25 & 54.3 & \\
\hline \multirow{2}{*}{ Pain during urination } & Yes & 34 & 54.0 & 29 & 46.0 & \multirow{2}{*}{0.067} \\
\hline & No & 5 & 100.0 & 0 & 0.0 & \\
\hline \multirow{2}{*}{ Nausea, vomiting, diarrhea and constipation } & Yes & 18 & 62.1 & 11 & 37.9 & \multirow{2}{*}{0.498} \\
\hline & No & 21 & 53.8 & 18 & 46.2 & \\
\hline \multirow{2}{*}{ Back ache } & Yes & 33 & 75.0 & 11 & 25.0 & \multirow{2}{*}{$0.000^{*}$} \\
\hline & No & 6 & 25.0 & 18 & 75.0 & \\
\hline \multirow{2}{*}{ Pain during sitting } & Yes & 39 & 62.9 & 23 & 37.1 & \multirow{2}{*}{$0.004^{*}$} \\
\hline & No & 0 & 0.0 & 6 & 100.0 & \\
\hline \multirow{2}{*}{ Pain down the legs } & Yes & 18 & 62.1 & 11 & 37.9 & \multirow{2}{*}{0.498} \\
\hline & No & 21 & 53.8 & 18 & 46.2 & \\
\hline
\end{tabular}

Table 6. The relationship between menstrual pattern and risk of endometriosis among participating girls.

\begin{tabular}{|c|c|c|c|}
\hline \multirow{2}{*}{ Item } & \multicolumn{2}{|l|}{ Endometriosis } & \multirow{2}{*}{ P-value } \\
\hline & Yes $(n=39)$ & No $(n=29)$ & \\
\hline \multicolumn{4}{|l|}{ Age at menarche } \\
\hline Mean \pm SD & $12.87 \pm 1.00$ & $13.45 \pm 0.78$ & $0.018^{*}$ \\
\hline Median (Range) & $12.0(12.0-14.0)$ & $14.0(12.0-14.0)$ & \\
\hline \multicolumn{4}{|c|}{ Duration of the flow } \\
\hline Mean \pm SD & $4.49 \pm 1.27$ & $4.21 \pm 0.77$ & 0.926 \\
\hline Median (Range) & $4.0(3.0-7.0)$ & $4.0(3.0-5.0)$ & \\
\hline \multicolumn{4}{|c|}{ Menstrual cycle duration (days) } \\
\hline Mean \pm SD & $26.97 \pm 2.02$ & $24.00 \pm 1.13$ & $0.001 *$ \\
\hline Median (Range) & $26.0(25.0-30.0)$ & $24.0(23.0-26.0)$ & \\
\hline \multicolumn{4}{|c|}{ Family history of endometriosis } \\
\hline Positive & $6(100.0 \%)$ & $0(0.0 \%)$ & $0.034 *$ \\
\hline Negative & $33(53.2 \%)$ & $29(46.8 \%)$ & \\
\hline
\end{tabular}

Fisher Exact Test * Statistical significant difference $(\mathrm{P}<0.05)$.

Table 6 scribes the relationship between the menstrual pattern among adolescent's girls and endometriosis. It was found that the younger age at menarche longer duration of menstrual cycle and positive family history of endometriosis are significant factors suggesting endometriosis among adolescent girls $(\mathrm{P}=0.018, \mathrm{p}=0.001, \mathrm{P}=0.034$ respectively).

Table 7. Comparison of the pain level and number of symptoms associating dysmenorrhea among adolescent's girls with suggested endometriosis before and after 3 months of hormonal treatment (pre and post-management).

\begin{tabular}{llll}
\hline Items & Pre-management (n=39) & Post-management (n=39) & P-value \\
\hline Level of pain & & & \\
Mild & $0(0.0 \%)$ & $17(43.8 \%)$ & $0.018^{*}$ \\
Moderate & $0(0.0 \%)$ & $11(28.2 \%)$ & $11(28.2 \%)$ \\
Severe & $39(100.0 \%$ & & $0.000^{*}$ \\
No. of associating symptoms & & $28(71.8 \%)$ & $11(28.2 \%)$ \\
$3-4$ & $0(0.0 \%)$ & & \\
5 or more & $39(100.0 \%$ &
\end{tabular}

Comparison of the level pain and number of symptoms associating dysmenorrhea among adolescent's girls with suggested endometriosis pre and post-management as displayed in table 7. There were statistically significant improvement of the level of pain and the number of symptoms associating dysmenorrhea among girls after three months of treatment (post-management) $(p=0.018$ and 0.000 , respectively). It was found that, while all girls (100\%) had severe dysmenorrhea before management, only $28.2 \%$ of them had severe dysmenorrhea at post-management 
indicating highly suspected endometriosis. Similarly while all girls (100\%) who suspected to have endometriosis by AUS reported five or more associating symptoms, only $28.2 \%$ of girls reported five or more pain features at postmanagement.

\section{Discussion}

Dysmenorrhea is a typical gynecological condition with difficult menstrual spasms of uterine root among young ladies. The present investigation demonstrated that, high rates of the member young women. The present study showed that, high percentages of the participant girls (79.3\%) experienced a variable degree of dysmenorrhea. This finding is reported by several studies with reporting rates between $28 \%$ and $89.5 \%$. [16, 17]. An Egyptian examination announced dysmenorrhea with variable level of seriousness among $48.9 \%$ of adolescent girls [18]. Similarly, in an investigation led in Kenya the predominance of dysmenorrhea was $70 \%$ among a similar age gathering of girls [19]. This variety in these appraisals might be identified with the variety of the strategies for gathering information, chose gathering of study, and nonattendance of a by and large acknowledged meaning of dysmenorrhea.

Furthermore, about two thirds $(64.9 \%)$ of the girls in the current study who experienced dysmenorrhea had the first menstrual pain at the range age $12-14$ years. This finding was supported by the fact that girls who attend menarche early have longer exposure to uterine prostaglandins leading to higher prevalence of dysmenorrhea [20].

When the pain level of dysmenorrhea was assessed by using VAS in this study, about two thirds of adolescents' girls reported moderate and severe dysmenorrhea. This reveals that, dysmenorrhea is still an important public health problem among adolescents. Comparative outcomes were accounted for by Unsal, et al, (2010) and Kural et al, (2015) who reported $66.2 \%$ and $70.2 \%$ respectively $[21,22]$.

The current study showed that, there were variable number of symptoms associating dysmenorrhea among the majority of girls. The Most frequent occurring symptoms were back ache, irregular menstruation and pain during sitting. Also, more than one quarter of the girls reported pain during urination and pain during bowel movement. Similar findings were demonstrated by by Kagia, (2017) ${ }^{19}$.

Besides, In this examination there was a positive correlation between number of symptoms associating dysmenorrhea and the pain level of dysmenorrhea as assessed by VAS. Similarly, Suvitie et al, (2016) reported that, severe dysmenorrhea was associated with increased risk of other symptoms as acyclic abdominal pain, dyspareunia, dyschezia and dysuria [23].

The aim of the present study was to evaluate severe dysmenorrhea for early recognition of endometriosis among adolescent girls. The results of the present study indicated that, more than half of girls who experienced severe dysmenorrhea ( 8 to 10 on VAS) and those who had five or more symptoms associating dysmenorrhea had positive ultrasound picture of endometriosis. This finding added an evidence that, girls with severe dysmenorrhea are highly suspected to have endometriosis. Therefor severe dysmenorrhea may be considered an early evidence to serash for endometriosis among young girls. This finding was also reported by Janssen et al, (2013) who confirmed that, the prevalence of endometriosis was $62 \%$ among girls with severe dysmenorrhea [24]. Also, in Nigerian study conducted by Fawole et al, (2015), young women with dysmenorrhea had a higher risk of being diagnosed as endometriosis than those who did not report dysmenorrhea [25].

Ultrasound examination either trans-vaginal or transabdominal is a solid device for recognizing endometriosis [4]. The present study showed that, positive ultrasonography picture of endometriosis was reported in more than half of girls with severe dysmenorrhea and who were suspected to have endometriosis. This result supported the evidence that, ultrasound examination could be used as an initial screening tool for endometriosis.

In this study, there was a significant relation between suffering from pelvic pain at any time, menorrhagia, irregular menstruation, pain during bowel movement, back ache and pain during sitting and suspected endometriosis. This finding was fortified by Kagia, (2017) who reasoned that, young ladies encountering dysphasia, acyclic abdominal pain, dysuria, irregular and heavy periods had a higher risk of being diagnosed as endometriosis [19]. Similar outcomes were accounted for by Ragab, et al, (2015) that, the commonest indications which were accounted for by cases suspected to have endometriosis were agonizing solid discharge or crap, difficult pee then queasiness and vomiting [18].

The present investigation, there was a positive family history of endometriosis among them, for example (mother or sister). Family ancestry of endometriosis is by all accounts an imperative hazard factor for young ladies to experience the ill effects of endometriosis. So also, Roman, (2010) inferred that, positive family ancestry of endometriosis would likewise be relied upon to build the rate of endometriosis among young girls [26].

While evaluating relationship between the adolescent's age of menarche and endometriosis in this study, the outcomes uncovered that, the adolescent girls who were younger at menarche have a significantly higher risk of endometriosis than those who were older. This finding was likewise revealed by Nnoaham et al, (2012) who broke down 18 casecontrol thinks about and reasoned that, early menarche expanded the danger of endometriosis [27].

Finally, this study might formulate baseline information for future researches in endometriosis among adolescence girls in the Upper Egypt. Strengths in this study included its prospective nature and multi-center study with reasonable number of cases included. Moreover, early detection for endometriosis in adolescent girls leads to early treatment that may reduce the long-term complications and improve the quality of life and their reproduction. As with any research, there are certain limitations of the study firstly, the nature of data was self-reporting, and it 
may have resulted in under-reporting of the conditions in few cases. Secondly, use of trans-abdominal ultrasonography in this study instead of trans-vaginal (because girls being virgins). Further, due to the limited resources and social constrains we did not perform other confirmatory investigations as MRI and laparoscopy for suspected girls.

\section{Conclusions and Recommendations}

Moderate and severe dysmenorrhea is common among adolescent. The girls who had severe dysmenorrhea and more than five symptoms associating dysmenorrhea as pelvic pain at any time, menorrhagia, irregular menstruation, pain during bowel movement, back ache and pain during sitting might be suspected to have endometriosis and therefore should be instructed to visit specialized gynecologist for further assessment. Further large scale study is essential with the use of more informative investigations as MRI and laparoscopy to gain accurate estimate of the prevalence of the disease and its types. Nurses may play an important role in raising the awareness of young girls with nature and course of the disease via direct contact in schools and hospitals using lectures, photos, handouts and videos.

\section{References}

[1] Acién P, Velasco I. Endometriosis: a disease that remains enigmatic. ISRN Obstet Gynecol. 2013; 17 242149. doi: $10.1155 / 2013 / 242149$.

[2] Di Paola V, Manfredi R, Castelli F, Negrelli R, Mehrabi S, Pozzi Mucelli R. Detection and localization of deep endometriosis by means of MRI and correlation with the ENZIAN score. Eur J Radiol. 2015844 568-574. doi: 10.1016/j.ejrad.2014.12.017.

[3] Mavrelos D, Saridogan E. Treatment of endometriosis in women desiring fertility. J Obstet Gynaecol India. 2015651 11-6. doi: 10.1007/s13224-014-0652-y.

[4] Saridogan E. Endometriosis in Teenagers. SAGE Journals, 2016115 705-709.

[5] Chapron, C, Lafay-Pillet, MC, Monceau, E. Questioning patients about their adolescent history can identify markers associated with deep infiltrating endometriosis. Fertil. Steril. $2011953877-881$.

[6] Fong Y, Hon S and Low L. The clinical profile of young and adolescent women with laparoscopically diagnosed endometriosis in a Singapore tertiary hospital. Taiwanese Journal of Obstetrics \& Gynecology 201756 181-183.

[7] Cosma S, Salgarello M, Ceccaroni M, Gorgoni G, Riboni F, La Paglia E, Danese S, enedetto C. Accuracy of a new diagnostic tool in deep infiltrating endometriosis: Positron emission tomography-computed tomography with $16 \alpha-[18 \mathrm{~F}]$ fluoro-17ß-estradiol. J Obstet Gynaecol Res. 20164212 1724-1733. doi: 10.1111/jog.13117.

[8] Verma SK, Lev-Toaff AS, Baltarowich OH, Bergin D, Verma M, Mitchell DG. Adenomyosis: sonohysterography with MRI correlation. AJR Am J Roentgenol. 20091924 1112-6. doi: 10.2214/AJR.08.1405.
[9] Bekiesińska-Figatowska, Magnetic resonance imaging as a non-invasive detection tool for extraovarian endometriosis-own experience. Ginekol Pol. 2014859 658-64.

[10] Bazot M, Bharwani N, Huchon C, et al. European society of urogenital radiology (ESUR) guidelines: MR imaging of pelvic endometriosis. Eur Radiol. 2017277 2765-2775. doi: 10.1007/s00330-016-4673-z.

[11] National Institute of Health and Care Excellence (NICE). Endometriosis; diagnosis and management. NICE guideline 2017. (nice.org.uk/guidance/ng73).

[12] Barrow, T. A., Liong, S. Y., Sukumar, Sathi Anandan. Complex abdominopelvic endometriosis: the radiologist's perspective. Abdominal Imaging. 2015407 2541-2556.

[13] Mao AJ, Anastasi JK. Diagnosis and management of endometriosis: the role of the advanced practice nurse in primary care. J Am Acad Nurse Pract. 2010222 109-16. doi: 10.1111/j.1745-7599.2009.00475.x.

[14] Yang, Y, Wang, Y, Yang, J, Wang, S, Lang, J. Adolescent endometriosis in China: a retrospective analysis of 63 cases. J. Pediatr. Adolesc. Gynecol. 2012255 295-299.

[15] Kim S, Yoon BI, Kim SJ, Cho HJ, Kim HS, Hong SH, Lee JY, Hwang TK, Kim SW. Effect of Oral Administration of Acetaminophen and Topical Application of EMLA on Pain during Transrectal Ultrasound-Guided Prostate Biopsy. $\begin{array}{lllllll}\text { Korean J Urol. } & 2011 & 52 & 7 & 452-6 . & \text { doi: }\end{array}$ 10.4111/kju.2011.52.7.452.

[16] Pitts MK, Ferris JA, Smith AM, Shelley JM, Richters J. Prevalence and correlates of three types of pelvic pain in a nationally representative sample of Australian women. Med J Aust. 200841893 138-43.

[17] Polat A, Celik H, Gurates B, Kaya D, Nalbant M, Kavak E. Prevalence of primary dysmenorrhea in young adult female university students. Arch Gynecol Obstet. 2009279 527-32.

[18] Ragab A, Shams M, Badawy A, Alsammani MA. Prevalence of endometriosis among adolescent school girls with severe dysmenorrhea: A cross sectional prospective study. Int J Health Sci (Qassim). 201593 273-81.

[19] Kagia, A. Prevalence of Pain Symptoms Suggestive of Endometriosis Among Adolescents in Kenya. Theses, College of Health Science, University of Nairobi 2017.

[20] Shrotriya C, Ray A, Ray S, Thomas GA. Menstrual characteristics and prevalence and effect of dysmenorrhea on quality of life in medical students. Int J Collab Res Intern Med Public Health, 20124 276-94.

[21] Unsal A, Ayranci U, Tozun M, Arslan G and Calik E. Prevalence of dysmenorrhea and its effect on quality of life among a group of female university students. Upsala Journal of Medical Sciences, 20101152 138-145.

[22] Kural MR, Noor NN, Pandit D, Joshi Tand Patil A. Menstrual characteristics and prevalence of dysmenorrhea in college going girls J Family Med Prim Care. 201543 426-431.

[23] Suvitie PA, Hallamaa MK, Matomäki JM, Mäkinen JI, Perheentupa AH. Prevalence of Pain Symptoms Suggestive of Endometriosis among Finnish Adolescent Girls (TEENMAPS study). J Pediatr Adolesc Gynecol. 2016292 97-103. 
[24] Janssen, EB, Rijkers, AC, Hoppenbrouwers, K, Meuleman, C, D'Hooghe, TM. Prevalence of endometriosis diagnosed by laparoscopy in adolescents with dysmenorrhea or chronic pelvic pain: a systematic review. Hum. Reprod. Update 2013 $195570-582$.

[25] Fawole AO, Bello FA, Ogunbode O, Odukogbe A-TA, Nkwocha GC, Nnoaham KE, et al. Endometriosis and associated symptoms among Nigerian women. Int J Gynaecol Obstet $20151302190-4$
[26] Roman, JD. Adolescent endometriosis in the Waikato region of New Zealand - a comparative cohort study with a mean follow-up time of 2.6 years. Aust. NZ J. Obstet. Gynaecol. 2010502 179-183.

[27] Nnoaham KE, Webster P, Kumbang J, Kennedy SH and Zondervan KT. Is early age at menarche a risk factor for endometriosis? A systematic review and meta-analysis of case-control studies. Fertil Steril; 2012983 702-712. 